\title{
A Model of Management towards the Excellence of Buddhist Sunday Schools
}

\author{
Phrasamu Komin Chanthapho (Inyoo) ${ }^{1}$, Intha Siriwan², Phramaha Sombat Dhanapanno ${ }^{3}$, Phramaha \\ Yannawat Thitavaddhano ${ }^{4}$ \\ ${ }^{1,2,3,4}$ Faculty of Education, Mahachulalongkornrajavidyalaya University \\ ${ }^{1}$ koinyoo1@gmail.com, ${ }^{2}$ intha.siri@mcu.ac.th, ${ }^{3}$ Sb20300@gmail.com, ${ }^{4}$ yannawat.bud@mcu.ac.th
}

\begin{abstract}
This research paper aimed to propose a model of management towards the excellence of Buddhist Sunday School. Mixed methods research was designed and it was divided into three steps. The first step was to study management using questionnaires to collect from 109 teachers, and data were analyzed by descriptive statistics such as percentage, mean and standard deviation. The second step was to develop the model by interview10 key informants with an interview form. The third step was to propose the model with focus group discussion of 9 experts. Data was analyzed by content analysis. The research study found that management model for the excellence of Buddhist Sunday School was a participatory school management (Bovorn) and was the development of people to become a complete human being, both body, mind, intelligence, knowledge, along with morality, ethics, and culture of living, able to live happily with others consists of 5 elements: 1) Principle, 2) Purpose, 3) Procedure system, 4) Action process consisted of (1) School management at Home (Ban), Temple (Wat), School (Rong-Rian) or called "Bovon" in Thai, (2) Participation in curriculum administration, (3) The teacher is acted as a person of learning, (4) The development of the learner to be a perfect human being of good, clever and happy, (5) Buddhist teaching management integrated with modern science, (6) clean, shady, safe learning resources linked to Thai wisdom, (7) Kalayanamit evaluation, and 5) Evaluation.
\end{abstract}

Keywords

Model of Management, Excellence, Buddhist Sunday School

Article Received: 10 August 2020, Revised: 25 October 2020, Accepted: 18 November 2020

\section{Introduction}

Thailand has a National Education Development Plan in 2017 to 2036 as a 20-year long-term plan to be a national strategic plan with a vision that "All Thai people receive quality education and lifelong learning, live happily in accordance with the principles of sufficiency economy and the change of the world in the 21 st century" to develop Thai society into a learning society and morality, ethics, knowledge, love and harmony and to cooperate in joining forces towards sustainable national development According to the philosophy of sufficiency economy the 20-year National Education Plan [1]. Then, there was subsequently promoted to monks and religious personnel, play a role in intellectual and psychological leadership, a good moral system, and a role in cultivating morals, values and behaviors suitable for Thai society.

Since society today has changed the economic structure Society and the environment causing the people's way of life and livelihoods to change rapidly, causing many problems including problems of deterioration from the moral value system, customs, traditions and national arts and culture. The moral and ethical decline that occurs in the minds of Thai people, as Somdet Puttakosacharn (Prayut Payutto) has said about the cause of social problems in sustainable development. Thailand seems to have more problems and a lot of crisis things happen too much emphasis on western development. Focusing on material and technology, the psychological development is inefficient and uneven. Thailand has to turn to developing more minds in order to reduce many social problems and moral degradation especially in the present day when all parties call for moral and moral development in Thai society [2].
Sunday Buddhist School is a source of education and training for children and youth of the nation in order to behave well and act according to the principles of Buddhist teachings, have respect and uphold the good cultural traditions of the nation so that it does not fade away because any nation if there is no own culture or his existence was not. Sunday Buddhist School Mahachulalongkornrajavidyalaya University established to meet the needs of parents or guardians of children and youth while Thai society is in a moral crisis. That is why the government agencies and related organizations need to meet together to resolve this issue [3].

In the past, many of the Sunday Buddhist schools have had some problems. Many in operation from the research results of Office of Moral and Ethics Development, Department of Religious Affairs, Ministry of Culture found that the educational management of current Sunday Buddhist School adhere to a fixed school framework causing unable to operate in accordance with the reality. As a result, management problems in both the administration of the school branches nationwide, the lack of continuous management as for the curriculum, there is still a lack of modernity as the teachers, most of the teachers are monks and novices who come to teach with faith, but may lack knowledge of teaching techniques, pedagogical psychology and may have several memorandums. Students are less likely to enroll in students from the family economy and lessened the interest of youths towards the education of Buddhism. Most of the teaching and learning aspects are based on a fixed teaching framework. Often inconsistent with the objective, evaluation principles, most of the curriculum assessments. Regarding the learning resources, the lack of places and factors in teaching media and 
equipment affected students' attendance which is why the trend of the number of branch schools and the number of students has decreased [4].

Nevertheless, the rate of the number of students completing the school curriculum based on the length of study from the first phase of the applicant's inquiry together with the rate of uncertainty each year. It can make the school cannot plan for appropriate manpower because there are 58 teachers, the proportion of the number of teachers per 21 students and the number of students is steadily decreasing comparing the academic year 2017 - 2018, the students decreased by 344 , accounting for $29 \%$ in all four fields at the end of teaching that not completely [5].

From research on the Sunday Buddhist Center, there were several problems found, namely the research of Phrabaideeka Sorachai Shinwaro, found that the management of the Sunday Buddhist Center in each area found weaknesses, problems, obstacles that should be developed, improved, as follows: Academic management of curriculum to have clear content and lead practical budgeting: allocating budgets to meet needs personnel aspects support personnel to have higher education. The general administration promotes an environment conducive to teaching and learning [6] and the research of Maha Suchart Dhammakamo that the results of the research found current condition, administration of Sunday Buddhist Study Center academic administration management lacking knowledge understanding of management principles. Teachers lack knowledge, expertise, lack of modern teaching techniques, budget management, received insufficient funds for management, need to get support from outside the budget to spend personnel management, monks and teachers were not enough, and lack of teaching expertise general administration. In the building used in the study, most of the teaching is done using the Sermon hall, the temple hall and the school classrooms inside the temple. The supporting budget in this area is not enough. The lack of support for its activities [7] demonstrates the need for research into the development of management to excellence for the Sunday Buddhist School to be able to solve such problems.

From the background and importance of the problem mentioned above. Therefore, the researcher has to research the management model towards excellence of the Sunday Buddhist School in order for the school to be developed to keep up with the changes to the 21 st century to operate in a modern system and suitable for the situation and to solve the management problems that will be beneficial to the Sunday Buddhist School.

\section{Research Objectives}

The objective of this research was to propose a management model for the excellence of the Sunday Buddhist School.

\section{Research Method}

Mixed methods research was designed and it was divided into three steps. The first step was to study management using questionnaires to collect from 109 teachers, and data were analyzed by descriptive statistics such as percentage, mean and standard deviation. The second step was to develop the model by interview10 key informants with an interview form. The third step was to propose the model with focus group discussion of 9 experts. Data was analyzed by content analysis. Details of each step was as follows:

Step 1 Study the management status of Sunday Buddhist School by studying the documents on the management of the Sunday Buddhist School. It was used to create a questionnaire to collect data from the research population, namely 109 teachers in Sunday Buddhism School, Mahachulalongkornrajavidyalaya University, and the entire population was used as a sample. The data were analyzed by statistical data such as percentage, mean and standard deviation.

Step 2: Develop a management model for the excellence of Sunday Buddhism School by studying documents related to the development of the management model towards excellence of the Sunday Buddhist School, and it was used to create interview points about the management of the Sunday Buddhist School of Excellence by 10 key informants in the interview and analyzed the data through content analysis.

Step 3: Propose a management model for the excellence of the Sunday Buddhist School. It is a qualitative research by organizing a focus group discussion with experts to determine the suitability of the model. The 9 experts participating in focus group discussion were selected according to specific qualifications with knowledge about the administration of the Sunday Buddhist School and perform data analysis with content analysis.

\section{Results}

A model of management towards the excellence of Buddhist Sunday School consists of 5 elements: 1) Principle, 2) Purpose, 3) Procedure system, 4) Action process which consisted of the process of operations in 7 areas and are as the following items.

1. School management at house, temple, and school (Bowon) consists of 1) administrative in the form of an educational institution committee. It consists of administrators, teachers, educational institution directors, monks, parents and qualified persons with various knowledge and experiences in order to jointly manage the school management. 2) Operate the joint management between house, temple, and school (Bowon), 3) mobilize resources for education as well as external speakers and qualified persons who are moral models for moral and moral training in schools. 4) Encourage communities and stakeholders to take part in the administration of educational institutions and organized by individuals, families, Buddhist organizations and other institutions providing education. 5) Promote the exchange of knowledge, interpersonal experience family, community, monk and local.

2. Participation in curriculum administration consists of 1) executing the curriculum. The school committee consists of administrators, teachers, educational institution committee members, monks, parents and qualified persons with various knowledge and experiences in order to join considering the curriculum designation, integration with the policies of the Sangha Association, Department of Religious Affairs, Ministry of Education and local wisdom. 3) Apply the curriculum to the teaching and learning management. 4) 
The curriculum should set clear objectives for the development of students to be good, smart and happy, and aims to develop learners to think and solve life problems.

3. The teacher is a person of learning, consisting of 1) the teacher plays a role in examining the coherence of the content prepared according to the problem and needs of the community and local wisdom to manage teaching and learning according to scope, content, standard, proportion of time. 3) Teachers have a direct role to play in curriculum development. It facilitates the learning of the learners. 5) Plan and evaluate learners' learning outcomes to obtain information that shows the real ability of learners, assess the learning outcome of the learners according to each learning standard, and use the assessment results for further development of learners.

4. Developing learners to be a complete and good, happy human consists of 1) learners participating in planning, organizing learning processes with parents and teachers. Plan their own learning according to aptitude. 2) Learners participate in the learning process that is consistent with their aptitudes, interests and abilities. 3) Learners have skills and have excellent ability, creative thinking, critical thinking, reasoning, and understanding of other people's ideas. 4) The students have the quality of being good, happy, being thoughtful, solving problems, adapting to the environment, society and the world. Integrating values into life recognize the importance of all things both in nature and in a complementary society able to be self-reliant in a constantly changing world and society.

5. The teaching and learning management of the Buddhist way integrated with modern science consists of 1) organizing a learning process by organizing content and activities in accordance with the Buddhist principles and delivering demonstrations of the Dharma and ethics to teach both in the room and outside the classroom. 3) Select teaching techniques suitable for the content and purpose of the curriculum. 4) Organize the learning process and bring local wisdom to participate in teaching and learning appropriately. 5) Educational personnel development related to the development of teaching materials learning innovation and educational technology to have knowledge, use skills and care for teaching materials.

6. Learning resources are clean, shady, safe, linked with Thai wisdom, consisting of 1) study the needs of learners to design learning resources that meet their needs, 2) prepare for accident prevention the emergence of students and stakeholders effectively, 3) find learning resources that are consistent with the curriculum by studying from real places in the areas of knowledge, memory, understanding and practical application, 4) to provide learning resources that modern simply emphasize the excellence of students according to the subject matter group, and enough and able to link the network for learning, 5) provide learning resources, teaching materials, learning innovation, and educational technology that students can apply in real life.

7. Kalyanamit evaluation consists of 1) organizing recording and reporting system to provide effective feedback to support students' learning, 2) develop tools for measuring and assessing results to meet standards, 3) evaluate teachers' teaching results for each academic year to bring results to improve teaching and learning continuously and systematically, 4) there are clear criteria for performance evaluation, outstanding practitioners were praised in the three main groups, good academic performance, good conduct, and service / dedication, 5) evaluation of satisfaction. evaluation of school performance in the management of education in an honest with transparent review.

The fifth component is evaluation that is a systematic analysis of data for decision making, improvement in management, model management by stakeholders, monks, parents, students or communities to participate as shown in Fig. 1.

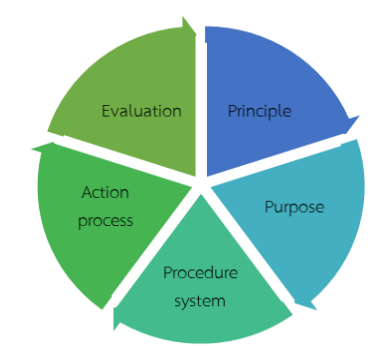

Fig. 1 A Model of Management towards the Excellence of Buddhist Sunday Schools

\section{Discussions}

This research found the following key points to discuss as follows.

Management Model for Excellence of Sunday Buddhist School, it is a participatory school management (Bowon) consisting of 5 elements: 1) Principle, 2) Purpose, 3) Action System, 4) Action Process, and 5) Evaluation. The results of this research are management. Sunday Buddhism School for excellence in 7 areas: (1) school management, house, temple and school (Bowon), (2) participation in curriculum administration, (3) teachers are people of learning, (4) Development of learners to be perfect, good, happy, (5) Buddhist teaching management integrated with modern science, (6) learning resources, clean, shady, safe, linked with Thai wisdom, (7) evaluation in which the results of the group discussions showed that it is appropriate and feasible to develop management to excellence in Sunday Buddhist School which will make it a management development and teaching and learning according to the school mission is to provide education to the youth and the general public and to preserve art and culture. It is a source of education and training for children and youth of the nation to have deep knowledge of Buddhism, and cultivate morality, ethics, and develop wisdom and mind to become a good and efficient Buddhist. This may be because Mahachulalongkornrajavidyalaya University has managed Sunday Buddhism School, Mahachulalongkornrajavidyalaya University has proceeded neatly and efficiently by dividing the department into a business style and adding more responsible officers. This is to make the Sunday Buddhist School a potential center with quality standards [8]. In addition, it is in line with the research of Phrabaidika Sorachai Shinwaro that the research results showed that the development of the administration of the Sunday Buddhist Center through strategic planning has set a vision to organize a Buddhist education to develop the minds of children and youth in Thailand with three missions: 1) to 
develop Buddhist studies for children and youth, 2) to develop youth to become a complete human being physical, social, mental and intellectual aspects, 3) aiming to produce youths to be good, smart and happy, and set four objectives: 1) Children and youth are good people and have virtue to bring knowledge and live happily, 2) Budget management in accordance with the plan and thoroughly support welfare, 3) Personnel with expertise, Thai arts and culture, and develop themselves on a regular basis, 4) The general administration system is efficient and effective [9], with the research of Phramaha Suchart Dhammakamo, the results of the research were found that cooperative management model for the Sunday Buddhist Center. It is the administration of all 4 aspects with the participation of all sectors in thinking, practice, decision making, benefit and monitoring by integration with Buddhist principles is academic aspect. Organized teaching and learning with the principle of Trisikkha for children is to develop 4 areas of budget management with selflessness, honesty and transparency, managing people with kindness, thinking, good thinking, optimism, kindness, speech, saying good things, kindness, acrobatics, doing good to each other and general administration. The Buddhist activities [10] were also found to be in line with Urairat Thongpinit's research of Model for promoting happiness for students in Sunday Buddhist School Mahachulalongkornrajavidyalaya University, it is a format that encourages and gives students the opportunity to make choices based on their individual interests and create an atmosphere of satisfaction in learning, making students happier, with the monks promoting and supporting, in collaboration with communities that are strong, cooperative and supportive [11] and related to the monks' research of Panuwat Patiphanmethee that the research results showed allocating sufficient funds for teaching materials provide a place that is sufficient for the number of students, and organize activities to engage more students provide teaching and learning with an emphasis on new innovations and recruiting competent personnel to educate students by using Mahachulalongkornrajavidyalaya University students as mentors to students of the Sunday Buddhism Study Center [12].

\section{Recommendations}

\section{A. Recommendations for Practices}

1. The public sector must set up a policy for all sectors, both public and private sectors that are related to Buddhism, and should support sufficient budget for their operations.

2. Ministry of Education Policy must be set for all sectors, both public and private sectors, to help develop teachers to have knowledge and understanding of Buddhism to develop a teacher for teaching Buddhism in general countries.

3. Mahachulalongkornrajavidyalaya University should support the budget for the Buddhist Sunday School sufficient for effective teaching and learning management.

4. Administrators of Sunday Buddhism School, the findings from the research on the management model for the excellence of the Sunday Buddhist School should be used in all 7 areas: 1) the administration, 2) the curriculum, 3) the teacher, 4) the learners, 5) teaching and learning, 6) learning resources, and 7) evaluation, to be a decision-making information for policy formulation for the management of the Sunday Buddhist school to be more effective.

\section{B. Recommendations for Further Research}

1. The administrators of Sunday Buddhism School should apply problems, methods and guidelines for organizational development in the administration to adapt to the environment and context within their school.

2. Administrators of Sunday Buddhism School Mahachulalongkornrajavidyalaya University in schools in various fields and should study in educational organizations, educational institutes, universities for comparison and appropriate application in their own school.

\section{Body Of Knowledge From Research}

From studying concepts and principles can be disassembled into a learning kit as follows:

\begin{tabular}{|c|c|}
\hline $\mathbf{K}$ & = Knowledge \\
\hline $\mathbf{O}$ & = Organization \\
\hline $\mathbf{M}$ & =Management Toward Excellence \\
\hline $\mathbf{I}$ & = International \\
\hline $\mathbf{N}$ & = New Norma \\
\hline
\end{tabular}

Fig.2 Knowledge gained from research KOMIN MODEL

\section{Conclusion}

Research paper on the management model for the excellence of the Sunday Buddhist School, it is a research that combines both quantitative research and qualitative research. There are 3 research steps which consist of the first step to study the management condition using the teacher questionnaire. For Step 2, the model was developed by interviewing the main informant, and the 3rd step, propose the model with a group of expert conclusion of the research results is a model for the management of excellence in the Buddhist Sunday School. It is the development of people to become a complete human body, mind, intelligence, knowledge along with morality and ethics and culture of living able to live happily with others. Its main elements are principles, aims, systems of execution, execution process and evaluation. The Summary of the body of knowledge from this research is KOMIN MODEL, namely $\mathrm{K}=$ Knowledge, knowledge in management of excellence, $\mathrm{O}=$ Organization, an educational organization that is the management of Sunday Buddhism School, $\mathrm{M}=$ Management toward excellence in management towards excellence in 7 areas: 1) School management at house, temple, and school (Bowon), 2) Participation in curriculum management, 3) teacher as a person of learning, 4) development learners to be human beings that are perfect, skillful, and happy, 5) Buddhist teaching management integrated with modern science, 6) learning resources clean, shady, safe, linked to Thai wisdom, and 7) evaluation of Kalayamit, I = International is the administration of the Sunday School of Buddhism to an international standard, and $\mathrm{N}=$ New Normal, a new normal, is the administration of 
the Sunday Buddhist School in the current situation facing COVID-19 that has changed the way of life and the way of life in the management of education and when it is repeated continuously, it becomes a familiar new normal.

\section{References}

[1] Office of the Education Council Secretariat Ministry of Education, National Education Plan 2017-2014, Bangkok: Prik Wan Graphic, 2017.

[2] Somdet Puttakosachan (P.A. Payutto), Sustainable Development, Bangkok: Komol Kiamthong Foundation, 2018.

[3] Sunday Buddhism School, 50 years of commemoration and ceremony of awarding certificates, diplomas, certificates and scholarships, Bangkok: Sahathikit, 2007.

[4] Office of Moral and Ethics Development, Department of Religious Affairs, Ministry of Culture, Patterns and administrative processes affecting the success of Sunday Buddhist Study Center, Bangkok: Publishing House of Agricultural Cooperatives of Thailand, 2007.

[5] Sunday Buddhism School, Presentation of Certificates, Certifications, Certificates and Scholarships, Bangkok: Mahachulalongkornrajavidyalaya

Publishing House, 2019.

[6] Phrabaidika Sorachai Shinawaro (Sakprasertporn), Strategy for Administration of Sunday Buddhist Study Center ", Ph.D. Dissertation, Graduate School, Mahachulalongkornrajavidyalaya University, 2016.

[7] Phramaha Suchart Dhammakamo, "Development of the Participatory Management Model of Sunday Buddhist Study Center in the Sangha Administrative Region, Region 13”, Doctor of Philosophy of Mahachulalongkornrajavidyalaya University, 2018.

[8] Mahachulalongkornrajavidyalaya University, Act, Regulations, Rules and Regulations,
Mahachulalongkornrajavidyalaya

Publishing House, 2011.

[9] Phrabidika Sorachai Shinawaro (Sak Prasertporn), Strategic Administration of Sunday Buddhist Studies Center, Doctor of Philosophy of Buddhism, Mahachulalongkornrajavidyalaya University, 2016.

[10] Phramaha Suchat Dhammakamo, Development of Participatory Management Model of Sunday Buddhist Study Center in the Sangha Administrative Area, Region 13, Ph.D. Dissertation, Graduate School, Mahachulalongkornrajavidyalaya University, 2018.

[11] U. Thongpinit, a model for promoting happiness for students in Sunday Buddhist School Mahachulalongkornrajavidyalaya University Doctor of Philosophy Degree of Buddhist Thesis, Mahachulalongkornrajavidyalaya University, 2018.

[12] Phra Mahaphanuwat Patiphanmethi, Administration of the Sunday Buddhist Study Center Lampang Province, Research Report, Mahachulalongkornrajavidyalaya University, 2013. 